\title{
SIMULACIÓN COMPUTACIONAL DE UN SISTEMA FRIGORÍFICO Y ANÁLISIS DE SUSTITUCIÓN DE REFRIGERANTES NOCIVOS A LA CAPA DE OZONO
}

\section{Boris Henry Rocha Mercado y Williams Gonzales Mamani}

\section{RESUMEN}

En el presente trabajo se desarrolla un modelo matemático para un sistema frigorífico en régimen permanente y una simulación computacional de su desempeño térmico. El sistema estudiado fue diseñado para trabajar con R-12 como fluido refrigerante y considera entre sus componentes un compresor hermético, condensador y evaporador de tubos y aletas, un tubo capilar, un separador de líquido y un filtro deshidratador. Los modelos matemáticos de los componentes del sistema fueron desarrollados considerando especificaciones técnicas de los fabricantes y correlaciones disponibles en la literatura. En el compresor de desplazamiento fijo se admite la presencia de un proceso de compresión politrópica, en el condensador y evaporador fueron consideradas las regiones monofásicas y bifásicas que define el fluido refrigerante a su paso por estos componentes y en el tubo capilar la variación de densidad y presión a lo largo de su longitud. La solución del sistema de ecuaciones resultante de los distintos modelos matemáticos, fue obtenida mediante el método de sustituciones sucesivas. Este modelo de simulación computacional fue utilizado para el análisis del desempeño térmico del Retrofit, donde se verifica una disminución de $6 \%$ en el COP por la substitución de R-12 por R-134a.

Palabras Clave: Sistema Frigorífico, Simulación, Modelado Matemático, Retrofit. 